\title{
The Equilibrium between Titanium Ions and Metallic Titanium in the Molten Binary Mixtures of LiCl
}

\section{Jianxun SONG, ${ }^{a}$ Qiuyu WANG, ${ }^{a}$ Minho KANG, ${ }^{a, b}$ Shuqiang JIAO, ${ }^{a, *}$ and Hongmin ZHUa,*}

a School of Metallurgical and Ecological Engineering, University of Science and Technology Beijing, No. 30 Xueyuan Road, Beijing, 100083, P. R. China

b School of Metallurgical Engineering, Kim Chaek University of Technology, Pyongyang, D P R Korea

*Corresponding authors: hzhu@metall.ustb.edu.cn, sjiao@ustb.edu.cn

\section{ABSTRACT}

The equilibrium constant, $K_{\mathrm{c}}$, of the reaction $3 \mathrm{Ti}^{2+}=2 \mathrm{Ti}^{3+}+\mathrm{Ti}$ was studied in the molten binary mixtures of $\mathrm{LiCl}$. The accurate values of $K_{\mathrm{c}}$ were calculated by the best-fitting method under consideration of the TiOCl(s) dissolution at temperature of $973 \mathrm{~K}, 1023 \mathrm{~K}$ and $1073 \mathrm{~K}$, respectively. The fitted concentration of $\mathrm{O}^{2-}$ was verified by emf method with yttria-stabilized zirconia electrode (YSZE). The influence of the cation radius of electrolyte on the equilibrium constant was studied in molten binary mixtures of $\mathrm{LiCl}$ at $1023 \mathrm{~K}$ on the basis of the reliable method for obtaining accurate value of $K_{\mathrm{c}}$. It was found that the $K_{\mathrm{c}}$ values decreased from 0.59 to 0.27 with the concentration of $\mathrm{LiCl}$ increasing at $1023 \mathrm{~K}$. More importantly, results disclosed that the values of $K_{\mathrm{c}}$ correspond with polarizing power no matter in $\mathrm{CsCl}-\mathrm{LiCl}$ or $\mathrm{KCl}-\mathrm{LiCl}$ system.

(c) The Electrochemical Society of Japan, All rights reserved.

Keywords : Equilibrium Constant, Oxide Content, Binary Mixtures, Polarizing Power

\section{Introduction}

The electrolysis processes for producing titanium are complicated due to the variety of titanium oxidation states. ${ }^{1-3}$ These oxidation states undergo disproportionation reactions leading to a low current efficiency and formation of metallic muds in molten cells. Therefore, the research on the equilibrium between titanium ions and metallic titanium is very important for the process of electrodepositing titanium from fused electrolytes. It has been reported that the equilibrium reaction can be expressed by the Re. (1):

$$
3 \mathrm{Ti}^{2+}=2 \mathrm{Ti}^{3+}+\mathrm{Ti}
$$

The equilibrium constant, $K_{\mathrm{c}}$, is defined by Eq. (2):

$$
K_{\mathrm{c}}=\frac{x^{2} \mathrm{Ti}^{3+} \cdot x_{\mathrm{Ti}}}{x^{3} \mathrm{Ti}^{2+}}=\frac{x^{2} \mathrm{Ti}^{3+}}{x^{3} \mathrm{Ti}^{2+}}
$$

Where $x_{\mathrm{i}}$ is the molar fraction of a species $i$, and it was defined by Eq. (3):

$$
x_{i}=\frac{n_{i}}{\sum n_{i}}
$$

The equilibrium constant of Re. (1) in different alkali chloride had been studied by some researchers. It was evaluated by Mellgren, Kreye, $\mathrm{Li}$, Sekimoto et al. with determining the concentrations of $\mathrm{Ti}^{2+}$ and $\mathrm{Ti}^{3+}$, respectively. ${ }^{4-9}$ Results show that the equilibrium constant dispersed under different experimental condition and increased significantly with the decreasing of the molar fraction of $\mathrm{Ti}^{2+}$. Actually, the $K_{\mathrm{c}}$ should be a constant as the solutes $\left(\mathrm{TiCl}_{3}\right.$, $\mathrm{TiCl}_{2}$ ) obey Henry's law under the condition of low titanium ions concentration. Such a tendency indicates that there is an underestimation of the concentration of $\mathrm{Ti}^{2+}$ or an overestimation of $\mathrm{Ti}^{3+}$ caused by some systematic errors or by the effect of some impurities in molten salt. According to the study of Sekimoto et al., ${ }^{7} \mathrm{Ti}^{3+}$ could reacts with $\mathrm{O}^{2-}$ and $\mathrm{Cl}^{-}$to form $\mathrm{TiOCl}(\mathrm{s})$. The ion of $\mathrm{Ti}^{3+}$ both in $\mathrm{TiOCl}(\mathrm{s})$ and in molten salt can be oxidized by the titrant agent, and they cannot be distinguished. Therefore, TiOCl(s) could cause overestimation of $\mathrm{Ti}^{3+}$ during chemical analysis, and the $\mathrm{O}^{2-}$ initially contained in molten salt could affect Eq. (1) which will lead to the $K_{\mathrm{c}}$ dispersed in molten salts. In the present study, the equilibrium constant was recalculated by the best-fitting method under consideration of the $\mathrm{TiOCl}(\mathrm{s})$ dissolution in molten binary mixtures of $\mathrm{LiCl}$. In order to verify the fitted results, the concentration of $\mathrm{O}^{2-}$ was disclosed by the yttria-stabilized zirconia electrode (YSZE).

Moreover, it has been reported in some papers that the stability of the various oxidation states depends on the composition bath ${ }^{10-14}$ which means different binary mixtures will show different equilibrium constant. Therefore, a series of experiments were carried out in molten binary mixtures of $\mathrm{LiCl}$ to clarify the influence of bath composition on the stability of the various oxidations. The polarizing power was introduced to reveal the correlation between solvent cations and equilibrium constant.

\section{Experiment Details}

\subsection{The preparation of electrolytes and samples}

The electrolyte were used in our experiments consisted of eutectic LiCl-CsCl (Sinopharm Chemical Reagent Co., Ltd. analytical grade $\geq 99.98 \%$ and $99.95 \%$, respectively) and $\mathrm{LiCl}-\mathrm{KCl}$ (Sinopharm Chemical Reagent Co., Ltd. analytical grade $\geq 99.98 \%$ and $99.98 \%$, respectively). They were predried in a vacuum chamber at $573 \mathrm{~K}$ for $24 \mathrm{~h}$ and then heated up to the fixed temperature under argon gas (Sinopharm Chemical Reagent Co., Ltd. analytical grade $\geq 99.90 \%$ ) atmosphere for $2 \mathrm{~h}$. Temperature control within $\pm 2 \mathrm{~K}$ was achieved by a digital temperature controller (CHINO DZ3000, CHINO Corporation, Tokyo, Japan) and measured by a K-type thermocouple (Omega Engineering, Inc., Stamford, CT).

The titanium subchloride salt were prepared by $\mathrm{TiCl}_{4}$ (Sinopharm Chemical Reagent Co., Ltd. analytical grade $\geq 99.90 \%)$ reacting with excess high pure titanium powder (Sinopharm Chemical Reagent Co., Ltd. analytical grade $\geq 99.90 \%$ ) in the eutectic molten salt according to the following reaction:

$$
(2-x / 2) \mathrm{Ti}+x / 2 \mathrm{TiCl}_{4} \rightarrow 2 \mathrm{TiCl}_{x}(x=2-3)
$$

Figure 1 shows the experimental apparatus for preparing the titanium subchloride salt and the sampler for taking samples. The 


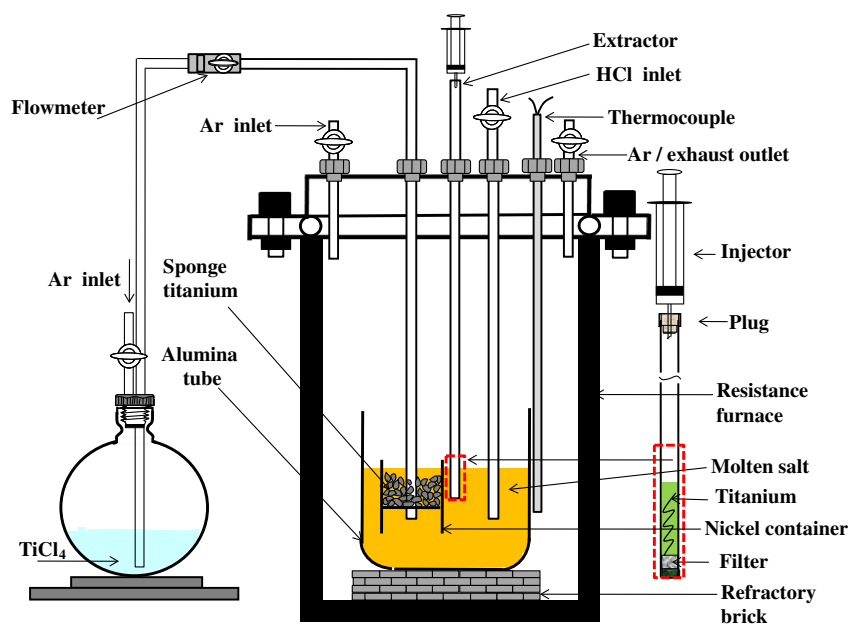

Figure 1. (Color online) Schematic diagram of equilibration apparatus.

prepared titanium subchloride and excess metallic titanium were held at a designed temperature to reach equilibrium. The argon gas was used to stir the molten salts for making the reaction of titanium ions and titanium metal adequately. ${ }^{13}$ Samples were taken by extracting the melts up into a piece of quartz tube $(\Phi 8 \mathrm{~mm} \times$ $500 \mathrm{~mm}$ ). The quartz filter was weld at the end of the quartz tube, and the fused salt could pass through it but titanium particles were filtered out. Meanwhile, titanium wire $(\Phi 0.3 \mathrm{~mm})$ was placed into the quartz tube to avoid breaking of the equilibrium reaction between metallic titanium and titanium ions when the dispersed titanium powders were filtered out by the quartz filter. ${ }^{9}$ After rapidquenching, samples were transferred to the glove box to await analysis. Four parallel samples were taken from fused salt for analysis in each experiment. The average values were considered to be the measured values of the concentration of titanium ions.

\subsection{Purification of the melt by means of gaseous $\mathrm{HCl}$ and determination of oxide content}

$\mathrm{HCl}$ gas was bubbled through the melts to remove $\mathrm{O}^{2-}$ dissolved in the molten salt at fixed temperature. The argon gas was introduced into the fused salt to remove excess $\mathrm{HCl}$ gas afterwards.

In order to establish the variation of oxide concentration during the purification of the melt, the calibration with YSZE ( $\Phi 3 \mathrm{~mm})$ was used. ${ }^{15-18}$ The reference electrode was an $\mathrm{Ag} / \mathrm{AgCl}$ electrode, which consisting of a silver wire $(\Phi 1 \mathrm{~mm})$ contained in a mullite tube and dipped into a silver chloride solution $(4 \mathrm{wt} \%)$ in the binary mixtures of LiCl. The auxiliary electrode was a graphite $\operatorname{rod}(\Phi 6 \mathrm{~mm})$. The variation of the YSZE potential was performed with emf method using an Autolab Princeton 263A potentiostat/galvanostat controlled with the PowerSuite software package. The Nernstian behaviour of the system was demonstrated by measuring the changes in electrode potential as purification with $\mathrm{HCl}$ gas. ${ }^{18}$ The relationship between concentration of oxide and potential is given by the Nernst relation Eq. (5):

$$
E_{\mathrm{O}_{2} / \mathrm{O}^{2-}}=E_{\mathrm{O}_{2} / \mathrm{O}^{2-}}^{*}-\frac{R T}{2 F} P_{\mathrm{O}^{2-}}
$$

where $E_{\mathrm{O}_{2} / \mathrm{O}^{2-}}$ is the equilibrium potential of $\mathrm{O}_{2} / \mathrm{O}^{2-}$ system (in $\mathrm{V}$ ); $E_{\mathrm{O}_{2} / \mathrm{O}^{2-}}^{*}$ is an apparent standard potential of the system (in $\mathrm{V}$ ), and $P_{\mathrm{O}^{2-}}$ is equal to $\ln x_{\mathrm{O}^{2-}}$.

It was necessary to calibrate the behavior of YSZE in the mixture $\mathrm{LiCl}-\mathrm{CsCl}(3: 2)$ before it was used. The variation of the YSZE potential can be determined when adding successive amounts of oxide ions into the bath. The oxide ions were introduced by means of known amounts of solid $\mathrm{Li}_{2} \mathrm{O}$. For this calibration the residual concentration of oxide ions present in the melt was taken into account. The response of the electrode is then:

$$
E_{\mathrm{O}_{2} / \mathrm{O}^{2-}}=E_{\mathrm{O}_{2} / \mathrm{O}^{2-}}^{*}-\frac{R T}{2 F} \ln \left(\mathrm{x}_{\mathrm{O}^{2-}}^{\text {add }}+\mathrm{x}_{\mathrm{O}^{2-}}^{\text {residual }}\right)
$$

The above calibration of the YSZE allows us to establish the variation of $P_{\mathrm{O}^{2-}}$ during the purification of the melt. Actually, it is $\mathrm{HCl}(\mathrm{g}) / \mathrm{H}_{2} \mathrm{O}(\mathrm{g})$ oxoacidic system and the reaction $\left(\mathrm{HCl}(\mathrm{g})+\mathrm{O}^{2-}=\right.$ $\mathrm{H}_{2} \mathrm{O}+2 \mathrm{Cl}^{-}$) occurs while testing.

\subsection{The determination of titanium ions concentration}

The quantitative analysis of different oxidation sates of titanium ions consists of three main steps. The concentrations of $\mathrm{Ti}^{2+}, \mathrm{Ti}^{3+}$ and $\mathrm{Ti}^{4+}$ in each sample were determined by $\mathrm{H}_{2}$ volumetric analysis, titration and spectrophotometry, respectively. The process of quantitative analysis was described as follows. First, the concentration of $\mathrm{Ti}^{2+}$ was measured by $\mathrm{H}_{2}$ volumetric analysis. The method is based on the fact that $\mathrm{TiCl}_{2}$ can react with hydrochloric acid and generates $\mathrm{H}_{2}$ gas in hydrochloric acid solution which is expressed by the following reaction:

$$
2 \mathrm{Ti}^{2+}+2 \mathrm{H}^{+} \rightarrow 2 \mathrm{Ti}^{3+}+\mathrm{H}_{2}(\mathrm{~g})
$$

The oxygen dissolved in diluted hydrochloric acid can oxidize $\mathrm{Ti}^{2+}$ in the process of determination of $\mathrm{Ti}^{2+}$, which can cause the underestimation of $\mathrm{Ti}^{2+}$ concentration in the sample. Vacuumdeaeration was used to remove the $\mathrm{O}^{2-}$ dissolved in deionized water. The deoxygenized hydrochloric acid solution was saturated by bubbling of high purity $\mathrm{H}_{2}$ to prevent the $\mathrm{H}_{2}$ generated by Re. (7) dissolving in the hydrochloric acid solution before the reaction. After the reaction, all of the $\mathrm{Ti}^{3+}$ in the solution consists of $\mathrm{Ti}^{3+}$ which is original in the sample and the $\mathrm{Ti}^{3+}$ generated by Re. (7). The concentration of $\mathrm{Ti}^{3+}$ in the solution was determined by the titrimetric analysis using $\mathrm{NH}_{4} \mathrm{Fe}\left(\mathrm{SO}_{4}\right)_{2}$ aqueous solution which was acidified with sulfuric acid. The $\mathrm{Ti}^{3+}$ in the solution reacts with $\mathrm{Fe}^{3+}$ as the reaction follows:

$$
\mathrm{Ti}^{3+}+\mathrm{Fe}^{3+} \rightarrow \mathrm{Ti}^{4+}+\mathrm{Fe}^{2+}
$$

The titration process was conducted in argon gas atmosphere. Finally, the total titanium ions $\left(\mathrm{Ti}^{2+}, \mathrm{Ti}^{3+}\right.$ and $\left.\mathrm{Ti}^{4+}\right)$ amount in the other solution were determined by diantipyrylmethane spectrophotometry. The concentration of $\mathrm{Ti}^{4+}$ from Re. (8) was equal to the concentration of $\mathrm{Ti}^{2+}$ plus $\mathrm{Ti}^{3+}$.

\section{Results and Discussion}

\subsection{The equilibrium between metallic $\mathrm{Ti}$ and $\mathrm{TiCl}_{2}, \mathrm{TiCl}_{3}$ in $\mathrm{LiCl}-\mathrm{CsCl}$ (3:2) salt}

The equilibrium constant, $K_{\mathrm{c}}$, was calculated in $\mathrm{LiCl}-\mathrm{CsCl}(3: 2)$ melts with different molar fraction of divalent titanium at different temperatures. Figure 2 shows the relationship between $K_{\mathrm{c}}$ values and the molar fraction of divalent titanium $\left(x_{\mathrm{Ti}^{2+}}\right)$ at $973 \mathrm{~K}, 1023 \mathrm{~K}$, and $1073 \mathrm{~K}$, respectively. It can be found that the equilibrium constant increased with the rising of temperature.

Figure 3 shows experiment data compared with the literature including the relationship between equilibrium constant and the molar fraction of divalent titanium at $973 \mathrm{~K}$. Obviously, the $K_{\mathrm{c}}$ values depend on the molar fraction of $\mathrm{Ti}^{2+}$, and it shows the similar regularity with other literatures in Fig. 3.

Sekimoto et al., ${ }^{8}$ Wang et al. ${ }^{10}$ and $\mathrm{Zhu}$ et al. ${ }^{13}$ considered that the initial $\mathrm{O}^{2-}$ in the melts could react with the $\mathrm{Ti}^{3+}$ and $\mathrm{Cl}^{-}$form $\mathrm{TiOCl}(\mathrm{s})$ which may overestimate the $\mathrm{Ti}^{3+}$ resulting in dispersing of the $K_{\mathrm{c}}$. The concentration of the initial $\mathrm{O}^{2-}$ is constant, the lower concentration of titanium ions is, the bigger effect of the $\mathrm{O}^{2-}$ on the

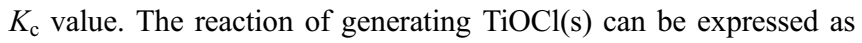
follows: 


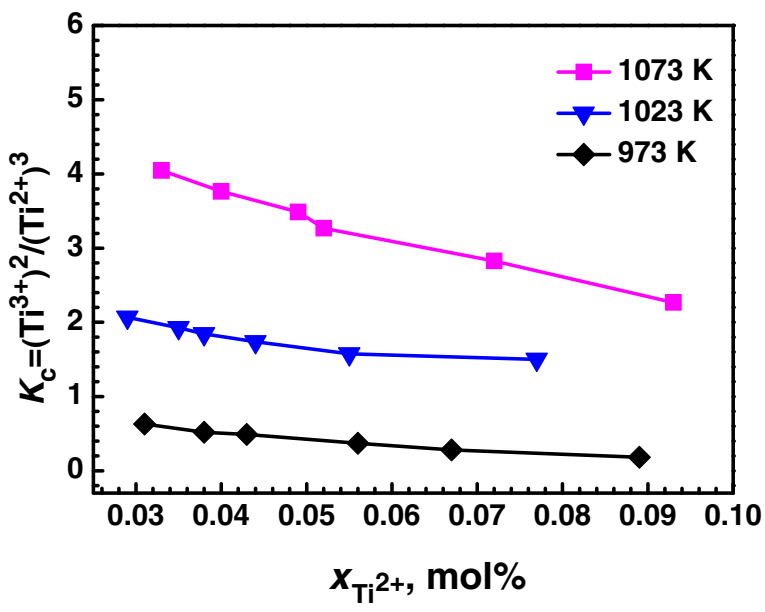

Figure 2. (Color online) The relationship between the $K_{\mathrm{c}}$ values and the concentrations of $\mathrm{Ti}^{2+}$ at different temperature.

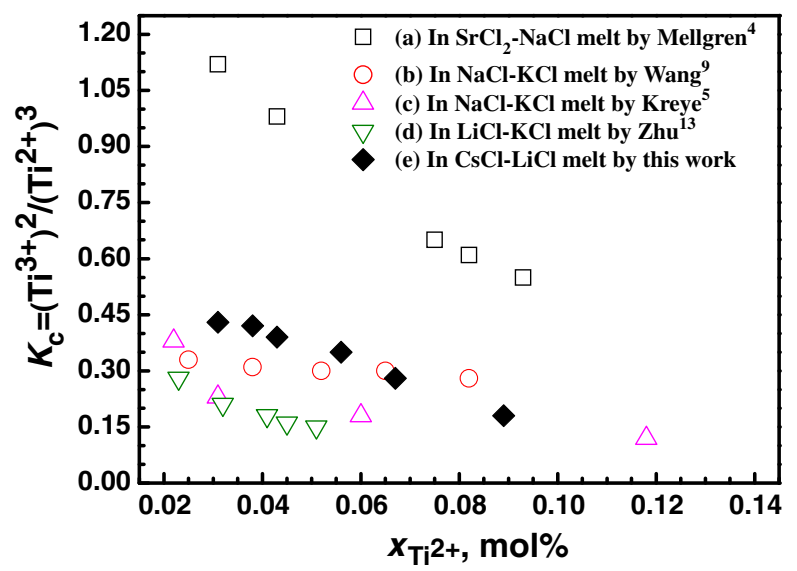

Figure 3. (Color online) The relationship between the $K_{\mathrm{c}}$ and $x_{\mathrm{Ti}^{2+}}$ of experiment data compared with the literature at $973 \mathrm{~K}$.

$$
\mathrm{Ti}^{3+}+\mathrm{O}^{2-}+\mathrm{Cl}^{-} \rightarrow \mathrm{TiOCl}(\mathrm{s})
$$

The solubility product of the $\mathrm{TiOCl}(\mathrm{s})$ is defined as the following expression:

$$
K_{\mathrm{sp}}=\frac{x_{\mathrm{O}^{2-}} x_{\mathrm{Ti}^{3+}} x_{\mathrm{Cl}^{-}}}{x_{\mathrm{TiOCl}}}=x_{\mathrm{O}^{2-}}^{\mathrm{eq}} x_{\mathrm{Ti}^{3+}}^{\mathrm{eq}}
$$

Where $x_{\mathrm{O}^{2-}}^{\text {eq. }}, x_{\mathrm{T}^{3+}}^{\text {eq. }}$ are the molar fraction of free $\mathrm{O}^{2-}$ and $\mathrm{Ti}^{3+}$ in the molten salt, respectively. The activities of chloride ion and TiOCl(s) are considered to be unity in the molten salt. The concentrations of $\mathrm{Ti}^{2+}, \mathrm{Ti}^{3+}$ were evaluated by the chemical methods are represented as $x_{\mathrm{Ti}^{2+}}^{\text {anal. }}$ and $x_{\mathrm{Ti}^{3+}}^{\text {anal. }}$. The equilibrium concentrations of $\mathrm{Ti}^{2+}, \mathrm{Ti}^{3+}$ are represented as $x_{\mathrm{Ti}^{2+}}^{\text {eq. }}$ and $x_{\mathrm{Ti}^{3+}}^{\text {eq. }}$. The relationship between $x_{\mathrm{Ti}^{2+}}^{\text {eq. }}, x_{\mathrm{Ti}^{3+}}^{\text {eq. }}$ and $x_{\mathrm{Ti}^{2+}}^{\text {anal. }}, x_{\mathrm{Ti}^{3+}}^{\text {anal. }}$ are as follows:

$$
\begin{aligned}
& x_{\mathrm{Ti}^{2+}}^{\text {anal. }}=x_{\mathrm{Ti}^{2+}}^{\text {eq. }} \\
& x_{\mathrm{Ti}^{3+}}^{\text {anal. }}=x_{\mathrm{Ti}^{3+}}^{\text {eq. }}+x_{\mathrm{TiOCl}}
\end{aligned}
$$

The mass balance of oxide is represented by Eq. (13):

$$
x_{\mathrm{O}^{2-}}^{\text {init. }}=x_{\mathrm{O}^{2-}}^{\text {eq. }}+x_{\mathrm{TiOCl}}^{\text {eq. }}
$$

$x_{\mathrm{Ti}^{3+}}^{\text {eq. }}$ was calculated by Eq. (14) using $x_{\mathrm{Ti}^{3+}}^{\text {anal. }}, x_{\mathrm{O}^{2-}}^{\text {init. }}$ and $K_{\mathrm{sp}}$.

$$
x_{\mathrm{Ti}^{3+}}^{\text {eq. }}=\frac{\left(x_{\mathrm{Ti}^{3+}}^{\text {anal. }}-x_{\mathrm{O}^{2-}}^{\text {init. }}\right)+\sqrt{\left(x_{\mathrm{Ti}^{3+}}^{\text {anal. }}-x_{\mathrm{O}^{2-}}^{\text {init. }}\right)^{2}+4 K_{\mathrm{sp}}}}{2}
$$

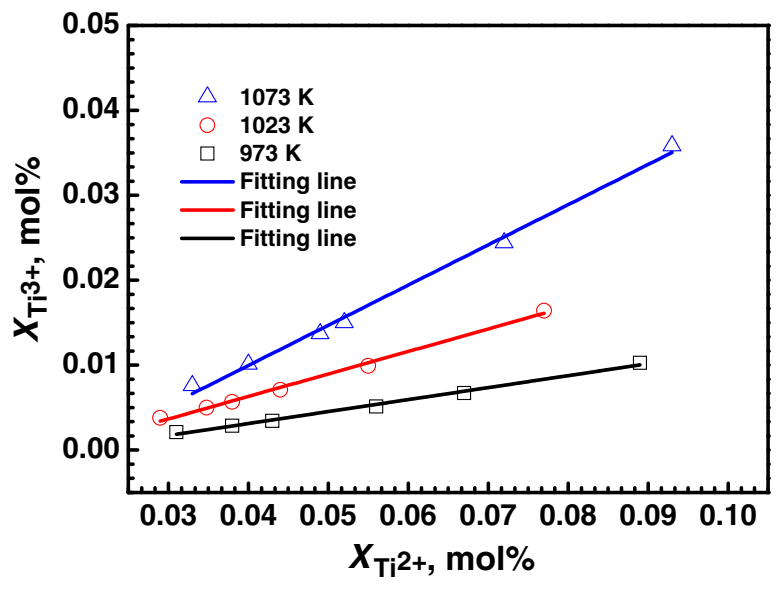

Figure 4. (Color online) The relationship between the best-fitting curve and the experiment data at different temperature.

Where $x_{\mathrm{O}^{2-}}^{\text {init. }}$ is the concentration of oxide initially dissolved in molten salt. According to Eq. (11) and Eq. (14), $x_{\mathrm{Ti}^{2+}}^{\text {eq. }}$ can be expressed as follow:

$$
x_{\mathrm{Ti}^{2+}}^{\text {eq. }}=\left\{\frac{\left[\left(x_{\mathrm{Ti}^{3+}}^{\text {anal. }}-x_{\mathrm{O}^{2-}}^{\text {init. }}\right)+\sqrt{\left(x_{\mathrm{Ti}^{3+}}^{\text {anal. }}-x_{\mathrm{O}^{2-}}^{\text {init. }}\right)^{2}+4 K_{\mathrm{sp}}}\right]^{2}}{4 K_{\mathrm{c}}}\right\}^{\frac{1}{3}}
$$

In Eq. (15), the $K_{\mathrm{c}}$ and $K_{\mathrm{sp}}$ are constant at a fixed temperature, and $x_{\mathrm{O}^{2-}}^{\text {init. }}$ is constant in the same electrolyte. In this work, $K_{\mathrm{c}}, K_{\mathrm{sp}}$, and $x_{\mathrm{O}^{2-}}^{\text {init. }}$ were set as the parameters, and Eq. (15) was employed to fit the experimental data $x_{\mathrm{Ti}^{+}}^{\text {anal. }}$ and $x_{\mathrm{Ti}^{3+}}^{\text {anal. }}$. Figure 4 shows the relationship between the best-fitting curve and the experiment data at different temperature. The best-fitting curves correspond well with the experiment data.

The results showing in Fig. 5(a) are the data that analyzed from the salt without purification, and results in Fig. 5(b) are that treated with $\mathrm{HCl}$. With comparison and analysis, the data without purification are more disperse than with the treatment. It is also observed that the fitting lines correspond well with the experimental data. The values of $K_{\mathrm{c}}, K_{\mathrm{sp}}$ and $x_{\mathrm{O}^{2-}}^{\text {init }}$ were calculated as the bestfitting parameters and the fitted results at different temperature are shown in Table 1.

All experimental data of $K_{\mathrm{c}}$ were revaluated back to a constant value that is equal to the best-fitting values which show in Fig. 5(a). They are $0.15,0.61$ and 1.59 at temperature of $973 \mathrm{~K}, 1023 \mathrm{~K}$ and $1073 \mathrm{~K}$, respectively. The values of $K_{\mathrm{sp}}$ were calculated to be $1.66 \times 10^{-5}, 2.64 \times 10^{-5}, 3.49 \times 10^{-5}$, at $973 \mathrm{~K}, 1023 \mathrm{~K}$ and $1073 \mathrm{~K}$, respectively. Figure 5(b) shows the results handled by best-fitting after purification with $\mathrm{HCl}$ gas. The $K_{\mathrm{c}}$ values at $973 \mathrm{~K}$, $1023 \mathrm{~K}$ and $1073 \mathrm{~K}$ were recalculated as $0.11,0.59$ and 1.58 , respectively. The values of $K_{\mathrm{sp}}$ were calculated to be $1.48 \times$ $10^{-5}, 2.39 \times 10^{-5}, 3.38 \times 10^{-5}$, at $973 \mathrm{~K}, 1023 \mathrm{~K}$ and $1073 \mathrm{~K}$, respectively.

The concentrations of $\mathrm{O}^{2-}$ in Table 1 were handled by best-fitting method with Eq. (15). It is revealed that the values of oxide concentration are $1187 \mathrm{ppm}, 1268 \mathrm{ppm}$ and $1291 \mathrm{ppm}$, respectively. The concentrations of oxide are $36 \mathrm{ppm}, 40 \mathrm{ppm}$ and $43 \mathrm{ppm}$ after purification with $\mathrm{HCl}$ gas. In order to prove the results ulteriorly, the variation of $P_{\mathrm{O}^{2-}}$ was disclosed by YSZE during the purification of the melt with $\mathrm{HCl}$ gas. The results show in Fig. 6. One can see from Fig. 6 that the residual concentration of $\mathrm{O}^{2-}$ in the melt after fusion under vacuum was about $1.0 \times 10^{-1.12} \mathrm{~mol} / \mathrm{kg}(1210 \mathrm{ppm})$. There is a rapid decrease for the oxide concentration which maintained a near constant value of $1.0 \times 10^{-5.73} \mathrm{~mol} / \mathrm{kg}(0.03 \mathrm{ppm})$ when the $\mathrm{HCl}$ 

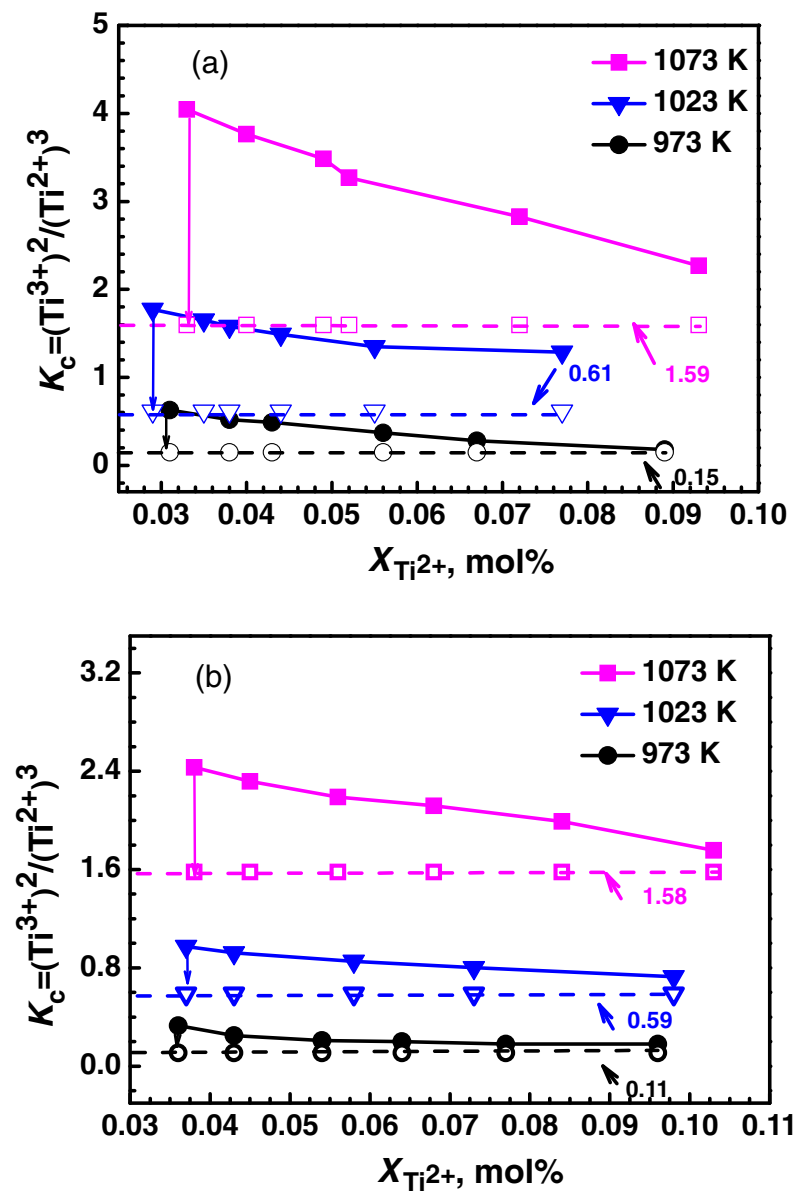

Figure 5. (Color online) Relationship between the $K_{\mathrm{c}}$ of the experiment data, and best-fitting parameters at $973 \mathrm{~K}, 1023 \mathrm{~K}$ and $1073 \mathrm{~K}$. (a) without $\mathrm{HCl}$ treatment; (b) with $\mathrm{HCl}$ treatment.

Table 1. Best-fitting parameters of $K_{\mathrm{c}}, K_{\mathrm{sp}}$, and $x_{\mathrm{O}^{2-}}^{\text {init. }}$ at different temperature and treatment.

\begin{tabular}{ccccc}
\hline $\begin{array}{c}\text { Temperature } \\
/ \mathrm{K}\end{array}$ & $\mathrm{HCl}$ treatment & $\begin{array}{c}K_{\mathrm{c}} \text { fitting } \\
\text { value }\end{array}$ & $\begin{array}{c}x_{\mathrm{O}^{2-}} \text { fitting } \\
\text { value } \\
/ \mathrm{ppm}\end{array}$ & $K_{\mathrm{sp}} \times 10^{5}$ \\
\hline 973 & without/with & $0.15 / 0.11$ & $1187 / 36$ & $1.66 / 1.48$ \\
1023 & without/with & $0.61 / 0.59$ & $1291 / 43$ & $2.64 / 2.39$ \\
1073 & without/with & $1.59 / 1.58$ & $1268 / 40$ & $3.49 / 3.38$ \\
\hline
\end{tabular}

gas was passed through the salt. There is a rapid increase for the concentration of $\mathrm{O}^{2-}$ as soon as argon gas was bubbled into the melt shown in Fig. 6. It reached to $1.0 \times 10^{-2.57} \mathrm{~mol} / \mathrm{kg}(43 \mathrm{ppm})$ owing to the traces of water contained in the argon gas and reacting with the salt according to Re. (16): ${ }^{15}$

$$
\mathrm{H}_{2} \mathrm{O}(\mathrm{g})+2 \mathrm{Cl}^{-} \rightarrow \mathrm{O}^{2-}+2 \mathrm{HCl}(\mathrm{g})
$$

Therefore, the residual oxide concentration is conditioned by the quality of the argon gas employed, a similar behavior observed in other molten chlorides.

In general, it can be draw the conclusion that the dispersed of equilibrium constant is influenced by oxide content in the melt, and the concentration of $\mathrm{O}^{2-}$ in the melt that calculated by best-fitting method is accordant well with the results determined by electrochemical method.

3.2 The influence of cation radius on the equilibrium constant In Fig. 3, it could be found that the values of $K_{\mathrm{c}}$ in $\mathrm{SrCl}_{2}-\mathrm{KCl}$ and

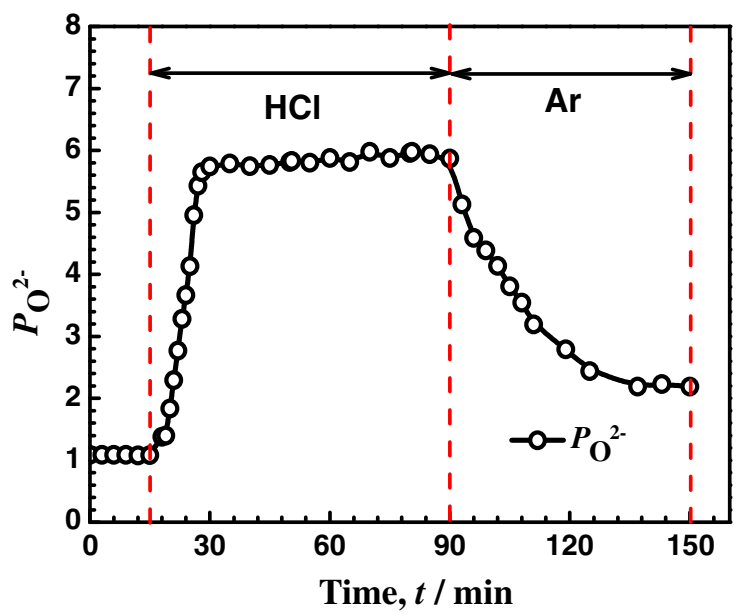

Figure 6. (Color online) Variation of the $P_{\mathrm{O}^{2-}}$ during the purification of the melt by $\mathrm{HCl}$ gas which measured with an oxide specific electrode based on YSZE.

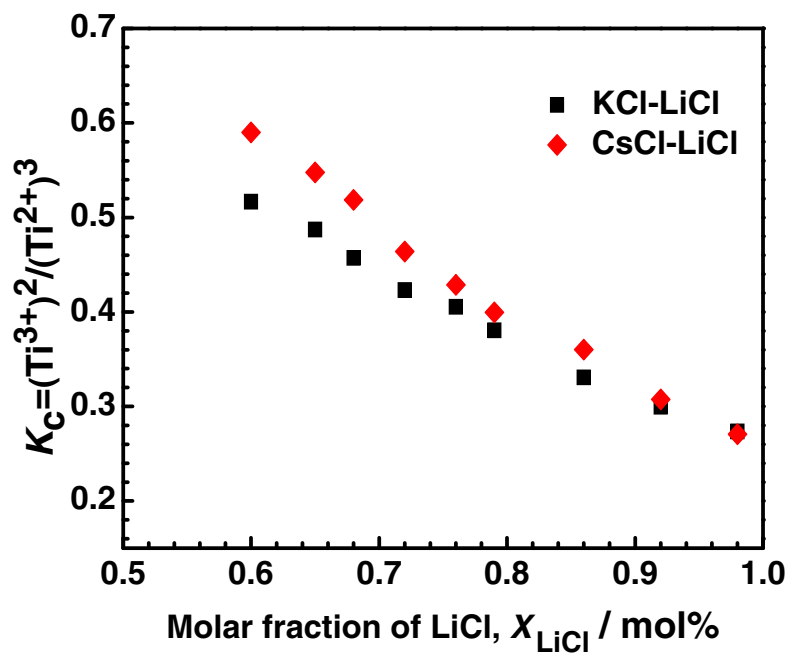

Figure 7. (Color online) The relationship between molar fraction of $\mathrm{LiCl}$ and equilibrium constant at $1023 \mathrm{~K}$.

$\mathrm{NaCl}-\mathrm{KCl}$ were bigger than that in $\mathrm{LiCl}-\mathrm{CsCl}(3: 2)$ at $973 \mathrm{~K}$ which means the value of $K_{\mathrm{c}}$ is related to the composition of electrolyte. In order to deliberate this phenomenon ulteriorly, the relationship between $K_{\mathrm{c}}$ and cation radius was studied. It should be noted that the $K_{\mathrm{c}}$ are the final results were analyzed by best-fitting method, and the concentrations of the titanium were controlled between $0.08 \mathrm{~mol} \%$ and $1.2 \mathrm{~mol} \%$. The results show in Fig. 7. It can be found that the values of $K_{\mathrm{c}}$ decreased with the increase of proportion of $\mathrm{LiCl}$ in molten binary mixtures at $1023 \mathrm{~K}$. Obviously, the composition of $\mathrm{LiCl}$ affected the relative proportions of the $\mathrm{Ti}^{2+}$ and $\mathrm{Ti}^{3+}$ in the melt.

Previous publications ${ }^{19-21}$ show that the stability of chlorocomplexes is strongly affected by different solvent cations. The ternary halides, such as $\mathrm{A}_{3} \mathrm{TiCl}_{6}$, have structures that depend on the cation $\left(\mathrm{A}^{+}\right)$added. One explanation may be described by a simple electrostatic model. Results in this study can be deduced that the titanium ions at their higher oxidation states are engaged in chlorocomplexes such as $\mathrm{TiCl}_{4}{ }^{-}$or $\mathrm{TiCl}_{6}{ }^{3-}$ from the model. Moreover, there is a competition between alkali metal and titanium ions to associate with chloride ions. The smaller ionic radius of the alkali metal ions are, the more strongly associate with $\mathrm{Cl}^{-}$, which results in a lesser stability of chlorocomplexes, and the 
Table 2. Ionic radius and polarizing power of cations.

\begin{tabular}{ccc}
\hline Ion & Ionic radius $r_{\mathrm{i}} / \AA^{22}$ & Polarizing power $P_{\mathrm{i}} / \AA^{-2}$ \\
\hline $\mathrm{Li}^{+}$ & 0.76 & 1.73 \\
$\mathrm{Na}^{+}$ & 1.02 & 0.96 \\
$\mathrm{~K}^{+}$ & 1.38 & 0.53 \\
$\mathrm{Cs}^{+}$ & 1.67 & 0.36 \\
\hline
\end{tabular}

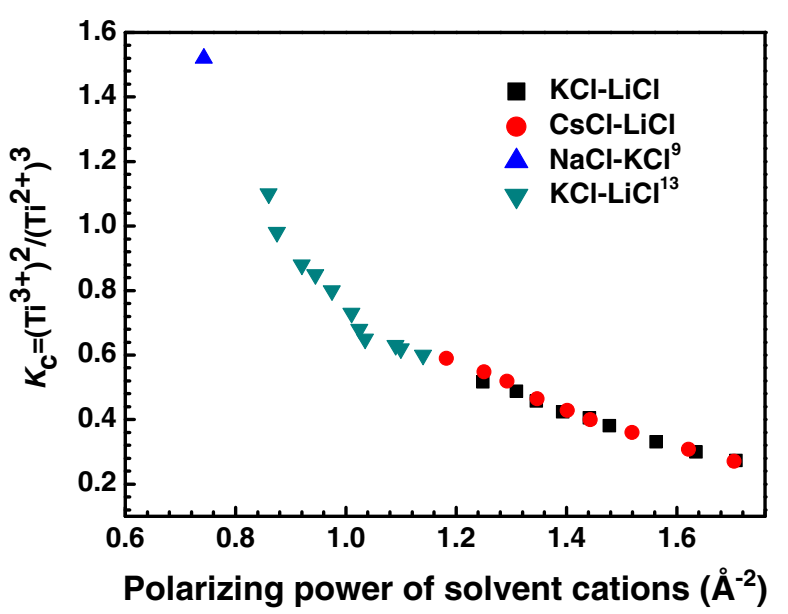

Figure 8. (Color online) The relationship between polarizing power of electrolyte and equilibrium constant at $1023 \mathrm{~K}$.

stability of the $\mathrm{Ti}^{2+}$ complex increased in the presence of outersphere cations in the series $\mathrm{Cs}^{+}$to $\mathrm{Li}^{+}$. In our case, the maximum $\mathrm{Ti}^{2+}$ complex stability is achieved in the presence of $\mathrm{Li}^{+}$outer sphere cations.

For mixtures of alkali chlorides, the polarizing ability of alkali cations to $\mathrm{Cl}^{-}$could be an average of each according to the mix ratio. Polarizing power, which is introduced for describing the numerous semi-quantitative relationships, involving the charge and the radius of the solvent cations can be present as this expression:

$$
P=\sum x_{\mathrm{i}} \frac{Z_{\mathrm{i}}}{r_{\mathrm{i}}^{2}}
$$

Where the suffix i represents the solvent cation; $Z_{\mathrm{i}}$ is the charge of the cation; $r_{\mathrm{i}}$ is the radius of it. The $r_{\mathrm{i}}$ and $P_{\mathrm{i}}$ values are shown in Table 2.

The relationships between equilibrium constant and polarizing power is shown in Fig. 8.

The values of $K_{\mathrm{c}}$ decreased with the enlargement of the polarizing power. The results disclosed that the $\mathrm{Ti}^{3+}$ is less stable in the alkali chloride with a stronger polarizing power. a The stronger polarizing power is, the closer of $\mathrm{Cl}^{-}$combine with the alkali cation. A larger polarizing power of electrolyte results in a lesser stability of $\mathrm{TiCl}_{6}{ }^{3-}$ and smaller $K_{\mathrm{c}}$ value. More importantly, the $K_{\mathrm{c}}$ is a constant value when polarizing power is constant regardless in $\mathrm{KCl}-\mathrm{LiCl}$ or $\mathrm{CsCl}-\mathrm{LiCl}$ at $1023 \mathrm{~K}$.

\section{Conclusions}

The research on the equilibrium between titanium ions and metallic titanium is very important for the process of electrodepositing of titanium from fused electrolytes. That is because of the variety of titanium oxidation states and these oxidation states undergo disproportionation reactions leading to a low current efficiency. The equilibrium constant, $K_{\mathrm{c}}$, for the reaction $3 \mathrm{Ti}^{2+}=$ $2 \mathrm{Ti}^{3+}+\mathrm{Ti}$ was studied in the molten binary mixtures of $\mathrm{LiCl}$. The accurate value of the equilibrium constant, the solubility product of $\mathrm{TiOCl}(\mathrm{s})$, and concentration of $\mathrm{O}^{2-}$ were calculated by the bestfitting method under the consideration of the $\mathrm{TiOCl}(\mathrm{s})$ dissolution. In the mixture of $\mathrm{LiCl}-\mathrm{CsCl}(3: 2)$, the $K_{\mathrm{c}}$ values are $0.13 \pm 0.02$ at $973 \mathrm{~K}, 0.60 \pm 0.01$ at $1023 \mathrm{~K}$ and $1.58 \pm 0.005$ at $1073 \mathrm{~K}$, respectively. The $K_{\mathrm{sp}}$ were calculated to be $1.57 \pm 0.09 \times 10^{-5}$, $2.52 \pm 0.13 \times 10^{-5}$ and $3.44 \pm 0.06 \times 10^{-5}$, at $973 \mathrm{~K}, 1023 \mathrm{~K}$ and $1073 \mathrm{~K}$, respectively. The concentration of $\mathrm{O}^{2-}$ that acquired by best-fitting method was verified by emf method with YSZE. The polarizing power was introduced to reveal the correlation between solvent cations and equilibrium constant, and results disclosed that a constant value of polarizing power corresponds with a constant $K_{\mathrm{c}}$ no matter in CsCl-LiCl or KCl-LiCl system.

\section{Acknowledgments}

This work was supported by National Science Foundation of China (No. 51322402), the Fundamental Research Funds for the Central Universities (No. FRF-TP-12-002B), National High Technology Research and Development Program of China (863 Program, No. 2012AA062302) and the Program for New Century Excellent Talents in University (NCET-11-0577).

\section{References}

1. M. B. Alpert, F. J. Schultz, and W. F. Sullivan, J. Electrochem. Soc., 104, 555 (1957).

2. G. M. Haarberg, W. Rolland, A. Sterten, and J. Thonstad, J. Appl. Electrochem., 23, 217 (1993).

3. S. Q. Jiao and H. M. Zhu, J. Alloys Compd., 438, 243 (2007).

4. S. Mellgren and W. Opie, J. Met., 9, 266 (1957).

5. W. C. Kreye and H. H. Kellogg, J. Electrochem. Soc., 104, 504 (1957).

6. H. Sekimoto, Y. Nose, T. Uda, and H. Sugimura, Mater. Trans., 51, 2121 (2010).

7. H. Sekimoto, Y. Nose, T. Uda, A. Uehara, H. Yamana, and H. Sugimura, J. Alloys Compd., 509, 5477 (2011).

8. H. Takamura, I. Ohno, and H. Numata, Jpn. Inst. Met., 60, 382 (1996).

9. Q. Y. Wang, J. X. Song, G. J. Hu, X. B. Zhu, J. G. Hou, S. Q. Jiao, and H. M. Zhu, Metall. Mater. Trans. B, 44, 906 (2013).

10. F. Lantelme, K. Kuroda, and A. Barhoun, Electrochim. Acta, 44, 421 (1998).

11. F. R. Clayton and G. Mamantov, J. Electrochem. Soc., 120, 1193 (1973).

12. N. Ene and S. Zuca, J. Appl. Electrochem., 25, 671 (1995).

13. X. B. Zhu, Q. Y. Wang, J. X. Song, J. G. Hou, S. Q. Jiao, and H. M. Zhu, J. Alloys Compd., 587, 349 (2014)

14. K. Fukasawa, A. Uehara, T. Nagai, T. Fuji, and H. Yamana, J. Alloys Compd., 414, 265 (2011).

15. R. F. Watson and G. S. Perry, J. Chem. Soc., Faraday Trans., 87, 2955 (1991).

16. D. Ferry, Y. Castrillejo, and G. Picard, Electrochim. Acta, 34, 313 (1989).

17. Y. Castrillejo, S. Palmero, R. Pardo, and P. S. Bataero, Electrochim. Acta, 38, 1743 (1993).

18. Y. Castrillejo, A. M. Martinez, G. M. Haarberg, B. Borresen, K. S. Osen, and R. Tunold, Electrochim. Acta, 42, 1489 (1997).

19. S. Senderoff, G. W. Mellors, and R. I. Bretz, J. Electrochem. Soc., 108, 93 (1961).

20. E. Chassaing, F. Basile, and G. Lorthioir, J. Appl. Electrochem., 11, 187 (1981).

21. E. Chassaing, F. Basile, and G. Lorthioir, J. Appl. Electrochem., 11, 193 (1981).

22. R. D. Shannon, Acta Crystallogr., Sect. A, 32, 751 (1976). 